\title{
Human Fire Legacies on Ecological Landscapes
}

\author{
Mitchell J. Power ${ }^{1,2,3,4 *}$, Brian F. Codding ${ }^{3,4}$, Alan H. Taylor ${ }^{5}$, Thomas W. Swetnam ${ }^{6}$, \\ Kate E. Magarga/3,4, Douglas W. Bird ${ }^{7}$ and James F. O'Connel/3,4 \\ ${ }^{1}$ Natural History Museum of Utah, University of Utah, Salt Lake City, UT, United States, ${ }^{2}$ Department of Geography, \\ University of Utah, Salt Lake City, UT, United States, ${ }^{3}$ Department of Anthropology, University of Utah, Salt Lake City, UT, \\ United States, ${ }^{4} \mathrm{Global}$ Change and Sustainability Center, University of Utah, Salt Lake City, UT, United States, ${ }^{5}$ Department \\ of Geography, Pennsylvania State University, University Park, PA, United States, ${ }^{6}$ Department of Anthropology, Pennsylvania \\ State University, University Park, PA, United States, ${ }^{7}$ Department of Geography and Development, University of Arizona, \\ Tucson, AZ, United States
}

\section{OPEN ACCESS}

Edited by: David K. Wright, Seoul National University,

South Korea

Reviewed by:

Fabien Arnaud,

Centre National de la Recherche Scientifique (CNRS), France

Li Wu,

Anhui Normal University, China

Gary E. Stinchcomb,

Murray State University, United States

*Correspondence:

Mitchell J. Power

mitchell.power@geog.utah.edu

Specialty section

This article was submitted to Quaternary Science, Geomorphology and Paleoenvironment, a section of the journal Frontiers in Earth Science

Received: 03 April 2018 Accepted: 20 September 2018 Published: 15 October 2018

Citation:

Power MJ, Codding BF, Taylor AH, Swetnam TW, Magargal KE, Bird DW and O'Connell JF (2018) Human Fire Legacies on Ecological Landscapes.

Front. Earth Sci. 6:151.

doi: 10.3389/feart.2018.00151
The primacy of past human activity in triggering change in earth's ecosystems remains a contested idea. Treating human-environmental dynamics as a dichotomous phenomenon - turning "on" or "off" at some tipping point in the past - misses the broader, longer-term, and varied role humans play in creating lasting ecological legacies. To investigate these more subtle human-environmental dynamics, we propose an interdisciplinary framework, for evaluating past and predicting future landscape change focused on human-fire legacies. Linking theory and methods from behavioral and landscape ecology, we present a coupled framework capable of explaining how and why humans make subsistence decisions and interact with environmental variation through time. We review evidence using this framework that demonstrates how human behavior can influence vegetation cover and continuity, change local disturbance regimes, and create socio-ecological systems that can dampen or even override, the environmental effects of local and regional climate. Our examples emphasize how a long-term interdisciplinary perspective provides new insights for assessing the role of humans in generating persistent landscape legacies that go unrecognized using a simple natural-versus-human driver model of environmental change.

Keywords: human legacy, interdisciplinary, anthropogenic fire, behavioral ecology, paleoecology

\section{INTEGRATING THE ECOLOGIES TO EXPLAIN PAST HUMAN-ENVIRONMENTAL DYNAMICS}

Increasing attention on the recent and significant impact of humans (e.g., Anthropocene) has focused ecological research on identifying how and when humans began to influence earth's ecosystems at geologic-scales (e.g., Zalasiewicz et al., 2008). There is a mounting urgency to identify sustainable solutions using historical contexts to shed light on how humans interacted with nature through time. The unprecedented environmental degradation now occurring around the globe has encouraged research into the complex linkages in time and space regarding how humans respond to change (see Costanza et al., 2007; Zhang et al., 2016). The growing evidence that humans have long had subtle (and even not so subtle) impacts on local and regional environmental variability is an emerging cross-disciplinary theme. Explaining this more subtle variation in past human-environmental dynamics (HED) is important if we are to uncover the true cause of human landscape legacies. Doing so requires a framework that can link evidence across human and 
biophysical ecology (i.e., behavioral ecology, community ecology, landscape ecology, historical ecology, and paleoecology) to identify the temporal and spatial scales of human impacts, and how behavior-environment interactions influence environmental legacies (Figure 1). While there is growing appreciation that large herbivores and predators can regulate ecosystem structure, humans are often overlooked as agents that influence trophic interactions, even at low densities with relatively simple technologies. There is increasing interdisciplinary (e.g., paleoecologists, ecologists, anthropologists, geographers) scholarship that is specifically targeting questions that might illuminate the antiquity and extent of human impacts and ecosystem engineering (Allendorf and Hard, 2009; McWethy et al., 2010; Bliege Bird, 2015; Boivin et al., 2016; Bull and Maron, 2016; Sullivan et al., 2017).

This growing body of work has identified important questions concerning the socio-ecological contexts that shape, and are shaped by, the use of natural resources by people. Behavioral ecology provides a core theoretical framework to evaluate assumptions on how humans interact with environmental variation based on short term, sometimes instantaneous, decisions about resource use (Bird et al., 2016). The aggregate of these decisions and their environmental outcomes are evident in archeological records over millennia and across continents (Codding and Bird, 2015). However, determining how and explaining why humans shape local environments requires linking these theoretical insights with new transdisciplinary approaches in environmental analysis. Specifically, integrating the social and ecological factors that shape how resource acquisition and consumption structure community assembly and biodiversity, can provide an explanation of how humans construct ecosystems (Stiner and Kuhn, 2016). Community and landscape ecology can be used to apply these insights to across coarser scales, and establish how human behaviors alter broad environmental patterning of habitat abundance and diversity (Mouillot et al., 2013). Methods and approaches from archeology and historical ecology (e.g., dendroecology) provide a framework to begin to explore these observations into the past, and contextualize humanenvironment interactions during recent centuries (e.g., Liebmann et al., 2016; Swetnam et al., 2016; Taylor et al., 2016). Finally, quaternary geology and paleoecology operate across a diverse array of spatiotemporal scales and captures environmental variation from the community to the continent from the recent past to deep time (Brücher et al., 2015). Notably, pollen analysis provides a cornerstone for understanding past vegetation and climate dynamics (e.g., Wright, 1974; Birks and Birks, 1980), including human landscape legacies (e.g., Foster et al., 1998; Delcourt and Delcourt, 2004; McWethy et al., 2010), that provide a foundation to contribute to conservation goals (Willis et al., 2010; Seddon et al., 2014). Combining these ecologies in a systematic framework provides a means to predict human behaviors that alter environments providing an opportunity to unpack the range of past humanenvironment interactions that ultimately elucidate the long-term and more subtle role of human-legacies in the earth system. Here we emphasize how this can be accomplished by combining behavioral models with empirical proxies of human impacts on fire regimes.

\section{THEORY AND METHODS FOR A NEW TRANS-DISCIPLINARY HED PERSPECTIVE}

When considering human populations through time, theoretical frameworks that explain human behavior can be coupled with methods from the environmental sciences to explain human environmental dynamics. In this example we use models of behavioral ecology that provide clear predictions of when and why people should use fire to increase encounter rates with high profitability resources (Codding and Bird, 2015), and examine the consequences of those decisions on vegetation dynamics. The benefits of burning likely outweigh costs in two particular contexts: low productivity environments where resources are naturally scarce, and high productivity environments where dense populations deplete resources (Figure 2). In low productivity environments such as hummock grasslands of Australia, Aboriginal foragers apply fire to increase encounter rates with small prey (Bliege Bird et al., 2013); while in high productivity tropical forests in Mesoamerica, Maya people apply fire to increase agricultural yields (Nigh and Diemont, 2013). While there will certainly be exceptions, these productivity extremes illustrate conditions where human fires have large influences on local ecosystems since wildfire frequencies are low where fuels are limited on one hand and climate conditions are limiting on the other (Pausas and Ribeiro, 2013; see Figure 2). In these examples, burning practices strongly influence ecosystem structure and increase biodiversity (Bliege Bird et al., 2013; Nigh and Diemont, 2013; Bird et al., 2016).

Building on this framework, trans-disciplinary case studies provide an opportunity to investigate human-environment interactions in the past. Integrating research that pairs archeological records with proximal paleoecological records (e.g., dendrochronology, fossil plant-, pollen- and charcoal-based sediment histories, phytolith and starch grain analysis, stable isotope analysis) and ethnographic research, could transform our understanding of the drivers of regional biodiversity and environmental change across a range of environments with varying levels of productivity. If validated, this approach provides a general framework to explain where, when, and how human subsistence generate lasting ecosystem legacies.

\section{AN EXAMPLE: VALIDATING HUMAN-FIRE-LANDSCAPE DYNAMICS IN THE PAST}

Using this integrated approach, we propose to untangle population-climate-subsistence-fire disturbance dynamics during the historic- prehistoric transition periods in western North America to test both the behavioral models with empirical proxies of human impacts on fire regimes. 


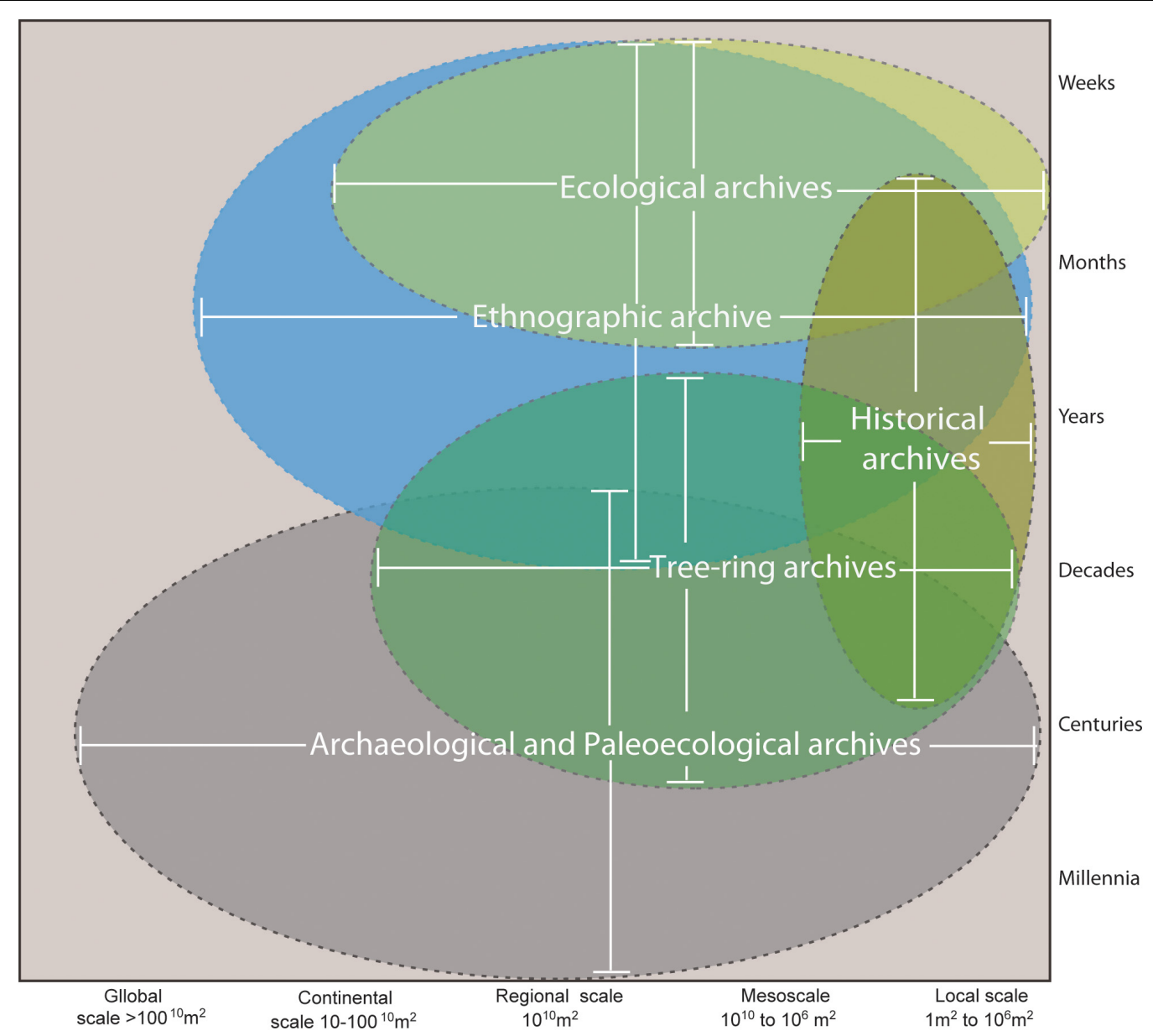

FIGURE 1 | Potential human-fire legacies may occur over a range of spatial and temporal domains. On the finest scales, ecological and ethnographic information provide local-to-continental site-specific knowledge from seasons-to-years. Ethnographic observations expand our temporal knowledge of human impacts to decades or longer. Understanding potential human-fire landscape changes over centuries, requires integrating historical archives that may include social, economic and environmental data, but are often spatially and temporally constrained. Tree-ring archives coupled with archeological and paleoecological records promote exploration of potential legacies across broader temporal and spatial domains. By combining disciplinary knowledge, a more robust representation of human legacies across space and time should emerge.

Two examples of such work emerge from recent case studies by Swetnam et al. (2016) and Taylor et al. (2016) where regional networks of fire-scarred tree-ring chronologies were linked to historical and archeological data in northern New Mexico and north-central California, respectively. They evaluate the interactions of people, forests and fire by exploring prehistoric and historic human land-use in parallel with ecological and climatic factors to provide a synthetic view of the drivers of fire regimes during the past $\sim 700$ years. Key findings indicate that fuel (vegetation cover) abundance and continuity were key controlling variables regulating frequent surface fire in pinedominant forests, and that human effects on fuel over-rode climate effects on fire regimes during periods with the highest human populations (e.g., changing the socio-ecological system) when resource competition and intensity of land use would be highest.

Disentangling the contribution of natural forcing and human activities on fire activity in the past requires this type of trans-disciplinary approach and supports our HED model. Historical and contemporary evidence of humanized ecosystems that utilize fire as a disturbance process to promote resource diversity is challenging our understanding of landscape change through time (e.g., Bird et al., 2016). In practice, combining disciplines that incorporate biotic and abiotic components with natural and human-driven processes to understand and interpret geographical landscapes is challenging. Regional studies that capture people, places, events, and processes in time provide limited insight when the cross-fertilization of knowledge is absent. The recent pairing of anthropology, archeology and dendroecology (e.g., Swetnam et al., 2016; Taylor et al., 2016), provide a powerful examples of integration of multiple disciplines to understand prehistoric cultures and how they interacted with their environment. Clearly, merging more disciplines within this theoretically informed approach will provide new opportunities for collaborative insight, creating a more comprehensive understanding of ecosystem dynamics 


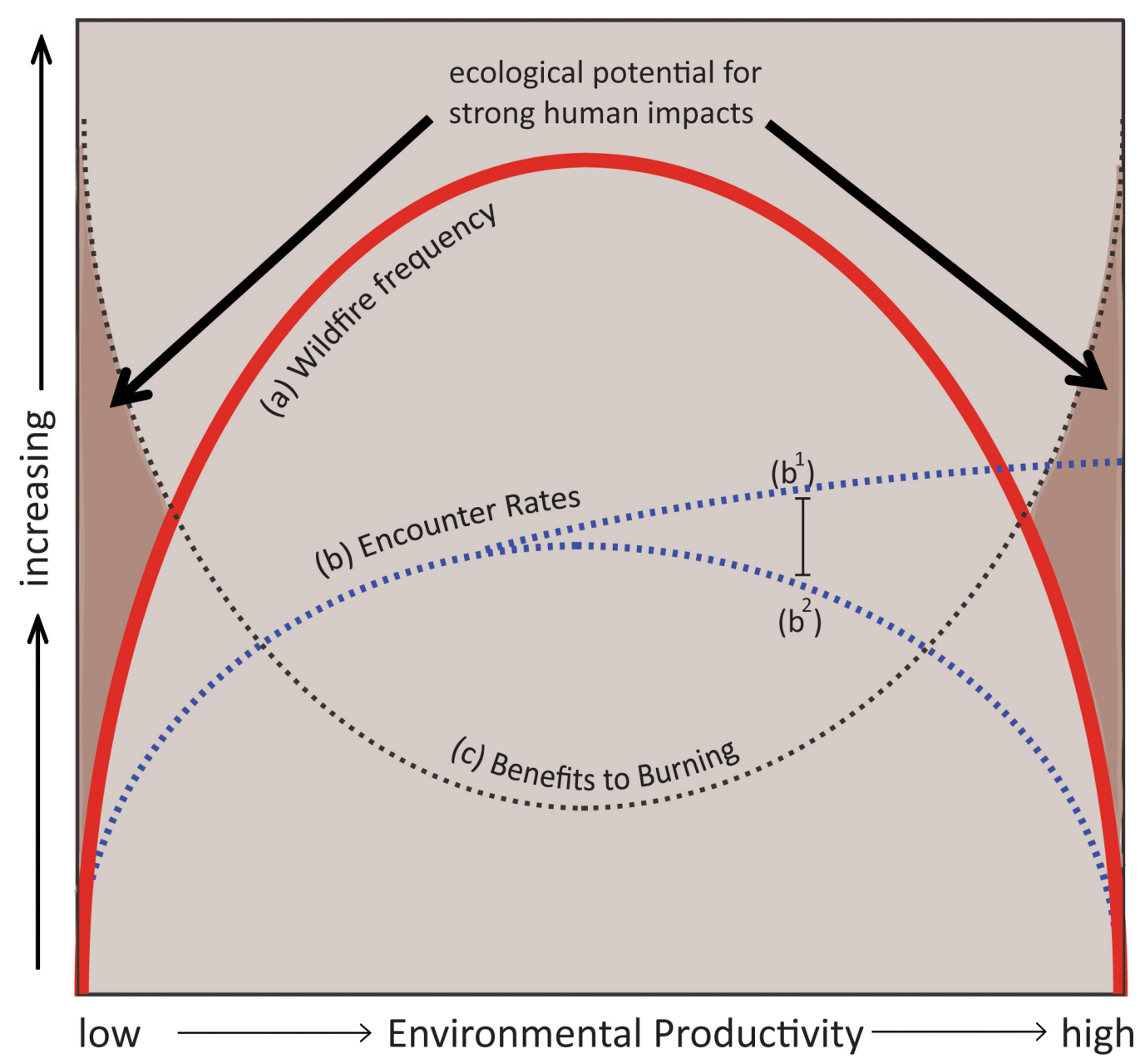

FIGURE 2 | Idealized patterns of (a) wildfire frequency and (b) profitable resource encounters, which drives (c) the benefits for applying fire, across the continuum of environmental productivity. Solid red line illustrates the empirically validated relationship (see Pausas and Ribeiro, 2013) noting that wildfire frequency is highest at intermediate levels of productivity, suggesting that human fires may have more room to influence ecosystems at the extremes of productivity (darker shaded areas). Dashed blue line illustrates proposed encounter rates small-scale human populations have with highly profitable resources, suggesting (c) motivations to burn in low productivity environments where resource are naturally scarce, and in high productivity environments once humans outstrip their food supply, presenting both the motivation and opportunity for significant human landscape legacies.

through time, and result in a more precise characterization of how and why human activities shape past, modern, and future landscapes.

\section{LOOKING TO THE FUTURE: MANAGEMENT IMPLICATIONS}

Establishing the scale of environmental impact by prehistoric societies has critical implications not only for archeology, anthropology and paleoecology, but also for ecology and conservation efforts geared toward restoring the ecological function of prehistoric people (Bliege Bird and Nimmo, 2018). In regions where people impact local biodiversity by selectively harvesting or promoting edible species or economically important species over others (e.g., Codding et al., 2014; Bird et al., 2016), local diversity may ultimately be a legacy of the past (e.g., Willis et al., 2007). A fundamental question in biology - what controls the distribution and abundance of species - may also be answered by considering human environmental dynamics. Four critical factors that likely limit the distribution of species, including, climate, species interactions, habitat and dispersal, are influenced by humans and contingent on spatial and temporal scale (e.g., McGill, 2010). A key message emerging from ecological research across multiple scales concludes that scale is relative to the specific organism and processes being considered.

The increasing prominence of fire with global change as temperatures continue to rise and regional droughts intensify (Moritz et al., 2012; Dennison et al., 2014) is forcing novel management approaches. In the case of reconstructing past fire regimes, a deeper understanding of human behavior is needed to improve predictive models of vegetation, biodiversity, and novel fire regimes under changing climates. Human activity can 
both override and amplify climate effects, but the ability to detect and evaluate human influence across multiple geographic scales (e.g., local to regional) remains a central challenge (e.g., Bowman et al., 2009; Mcwethy et al., 2013). As disciplines merge under a framework capable of explaining human environmental dynamics, research will provide more robust management strategies that consider the ecological position of fire in promoting and preserving biodiversity and human livelihoods in the future.

\section{CONCLUDING REMARKS}

Humans are now the most important agent of change on the planet; yet deciphering the role of humans on landscape change over the past millennia remains an elusive challenge. Here we have outlined a conceptual and empirical framework based on scale and opportunity to identify potential human legacies of landscape manipulation using the example of fire. Greater efforts are needed across disciplines to untangle the agents of change through time, and we hope the model presented here provides a springboard for biophysical and cultural scientists to engage with conservationists and land managers to identify the contribution of human legacies on today's landscapes.

\section{REFERENCES}

Allendorf, F. W., and Hard, J. J. (2009). Human-induced evolution caused by unnatural selection through harvest of wild animals. Proc. Natl. Acad. Sci. U.S.A. 106, 9987-9994. doi: 10.1073/pnas.0901069106

Bird, D. W., Bliege Bird, R. B., Codding, B. F., and Taylor, N. (2016). A landscape architecture of fire: cultural emergence and ecological pyrodiversity in Australia's Western Desert. Curr. Anthropol. 57, S65-S79. doi: 10.1086/ 685763

Birks, H. J. B., and Birks, H. H. (1980). Quaternary Palaeoecology. London: Edward Arnold, 289.

Bliege Bird, R. (2015). Disturbance, complexity, scale: new approaches to the study of human-environment interactions. Annu. Rev. Anthropol. 44, 81-87.

Bliege Bird, R., and Nimmo, D. (2018). Restore the lost ecological functions of people. Nat. Ecol. Evol. 2, 1050-1052. doi: 10.1038/s41559-018-0576-5

Bliege Bird, R., Taylor, N., Codding, B. F., and Bird, D. W. (2013). Niche construction and Dreaming logic: aboriginal patch mosaic burning and varanid lizards (Varanus gouldii) in Australia. Proc. R. Soc. Lond. B Biol. Sci. 280:20132297. doi: 10.1098/rspb.2013.2297

Boivin, N. E., Zeder, M. A., Fuller, D. Q., Crowther, A., Larson, G., Erlandson, J. M., et al. (2016). Ecological consequences of human niche construction: examining long-term anthropogenic shaping of global species distributions. Proc. Natl. Acad. Sci. U.S.A. 113, 6388-6396. doi: 10.1073/pnas.1525200113

Bowman, D. M. J. S., Balch, J. K., Artaxo, P., Bond, W. J., Carlson, J. M., Cochrane, M. A., et al. (2009). Fire in the earth system. Science 324, 481-484. doi: 10.1126/ science. 1163886

Brücher, T., Brovkin, V., Kloster, S., Marlon, J. R., and Power, M. J. (2015). How to compare modeled fire dynamics with charcoal records? Past Glob. Chang. Mag. $23,16-17$.

Bull, J. W., and Maron, M. (2016). How humans drive speciation as well as extinction. Proc. R. Soc. Lond. B Biol. Sci. 283:20160600. doi: 10.1098/rspb.2016. 0600

Codding, B. F., and Bird, D. W. (2015). Behavioral ecology and the future of archaeological science. J. Archaeol. Sci. 56, 9-20. doi: 10.1016/j.jas.2015.02.027

\section{AUTHOR CONTRIBUTIONS}

MP and $\mathrm{BC}$ drafted the initial manuscript after several days of discussion with AT, TS, KM, DB, and JO at a Taos, NM workshop. All co-authors equally edited the manuscript and provided suggestions, references, and improvements.

\section{FUNDING}

Funding for the Taos Summit on Human Ecological Dynamics, organized by Douglas Bird. Additional funding for this project comes from National Science Foundation (DEB- 1714972) and the University of Utah Vice President for Research.

\section{ACKNOWLEDGMENTS}

We thank our colleagues for thoughtful discussions during the Taos Summit funded by the Center for Human Ecology at Penn State University where many of these ideas were developed. This piece benefited from the detailed reviews of three peers. This manuscript also benefited from discussions with members of the Global Paleofire Working Group, a PAGES-sponsored working group.

Codding, B. F., Bliege Bird, R., Kauhanen, P. G., and Bird, D. W. (2014). Conservation or Co-evolution? Intermediate levels of Aboriginal burning and hunting have positive effects on kangaroo populations in Western Australia. Hum. Ecol. 42, 659-669. doi: 10.1007/s10745-014-9682-4

Costanza, R., Graumlich, L., Steffen, W., Crumley, C., Dearing, J. A., Hibbard, K., et al. (2007). Sustainability or Collapse: what can we learn from integrating the history of humans and the rest of nature? AMBIO A J. Hum. Environ. 36, 522-527. doi: 10.1579/0044-7447(2007)36[522:SOCWCW]2.0.CO;2

Delcourt, P. A., and Delcourt, H. R. (2004). Prehistoric Native Americans and Ecological Change: Human Ecosystems in Eastern North America since the Pleistocene. Cambridge: Cambridge University Press, 216. doi: 10.1017/ CBO9780511525520

Dennison, P. E., Brewer, S. C., Arnold, J. D., and Moritz, M. A. (2014). Large wildfire trends in the western United States, 1984-2011. Geophys. Res. Lett. 41, 2928-2933. doi: 10.1002/2014GL059576

Foster, D. R., Motzkin, G., and Slater, B. (1998). Land-use history as long-term broad-scale disturbance: regional forest dynamics in central New England. Ecosystems 1, 96-119. doi: 10.1007/s100219900008

Liebmann, M. J., Farella, J., Roos, C. I., Stack, A., Martini, S., and Swetnam, T. W. (2016). Native American depopulation, reforestation, and fire regimes in the Southwest United States, 1492-1900 CE. Proc. Natl. Acad. Sci. U.S.A. 113, E696-E704. doi: 10.1073/pnas.1521744113

McGill, B. J. (2010). Matters of scale. Science 328, 575-576. doi: 10.1126/science. 1188528

Mcwethy, D. B., Higuera, P. E., Whitlock, C., Veblen, T. T., Bowman, D. M. J. S., Cary, G. J., et al. (2013). A conceptual framework for predicting temperate ecosystem sensitivity to human impacts on fire regimes. Glob. Ecol. Biogeogr. 22, 900-912. doi: 10.1111/geb.12038

McWethy, D. B., Whitlock, C., Wilmshurst, J. M., McGlone, M. S., Fromont, M., Li, X., et al. (2010). Rapid landscape transformation in South Island, New Zealand, following initial Polynesian settlement. Proc. Natl. Acad. Sci. U.S.A. 107, 21343-21348. doi: 10.1073/pnas.1011801107

Moritz, M. A., Parisien, M. A., Batllori, E., Krawchuk, M. A., Van Dorn, J., Ganz, D. J., et al. (2012). Climate change and disruptions to global fire activity. Ecosphere 3, 1-22. doi: 10.1890/ES11-00345.1 
Mouillot, D., Graham, N. A., Villéger, S., Mason, N. W., and Bellwood, D. R. (2013). A functional approach reveals community responses to disturbances. Trends Ecol. Evol. 28, 167-177. doi: 10.1016/j.tree.2012.10.004

Nigh, R., and Diemont, S. A. (2013). The Maya milpa: fire and the legacy of living soil. Front. Ecol. Environ. 11, e45-e54. doi: 10.1890/120344

Pausas, J. G., and Ribeiro, E. E. (2013). The global fire-productivity relationship. Glob. Ecol. Biogeogr. 22, 728-736. doi: 10.1111/geb.12043

Seddon, A. W. R., Mackay, A. W., Baker, A. G., Birks, H. J. B., Breman, E., Buck, C. E., et al. (2014). Looking forward through the past: identification of 50 priority research questions in paleoecology. J. Ecol. 102, 256-267. doi: 10.1111/1365-2745.12195

Stiner, M. C., and Kuhn, S. L. (2016). Are we missing the "sweet spot" between optimality theory and niche construction theory in archaeology? J. Anthropol. Archaeol. 44, 177-184. doi: 10.1016/j.jaa.2016. 07.006

Sullivan, A. P., Bird, D., and Perry, G. H. (2017). Human behavior as a longterm ecological driver of non-human evolution. Nat. Ecol. Evol. 1:0065. doi: 10.1038/s41559-016-0065

Swetnam, T. W., Farella, J., Roos, C. I., Liebmann, M. J., Falk, D. A., and Allen, C. D. (2016). Multiscale perspectives of fire, climate and humans in western North America and the Jemez Mountains, USA. Philos. Trans. R. Soc. B Biol. Sci. 371:20150168. doi: 10.1098/rstb.2015.0168

Taylor, A. H., Trouet, V., Skinner, C. N., and Stephens, S. (2016). Socioecological transitions trigger fire regime shifts and modulate fire-climate interactions in the Sierra Nevada, USA 1600-2015 CE. Proc. Natl. Acad. Sci. U.S.A. 113, 13684-13689. doi: 10.1073/pnas.1609775113

Willis, K. J., Araújo, M. B., Bennett, K. D., Figueroa-Rangel, B., Froyd, C. A., and Myers, N. (2007). How can a knowledge of the past help to conserve the future? Biodiversity conservation and the relevance of long-term ecological studies. Philos. Trans. R. Soc. B Biol. Sci. 362, 175-187. doi: 10.1098/rstb.2006. 1977

Willis, K. J., Bailey, R. M., Bhagwat, S. A., and Birks, H. J. B. (2010). Biodiversity baselines, thresholds and resilience: testing predictions and assumptions using paleoecological data. Trends Ecol. Evol. 25, 583-591. doi: 10.1016/j.tree.2010.07. 006

Wright, H. E. (1974). Landscape development, forest fires, and wilderness management. Science 186, 487-495. doi: 10.1126/science.186.41 63.487

Zalasiewicz, J., Williams, M., Smith, A., Barry, T. L., Coe, A. L., Bown, P. R., et al. (2008). Are we now living in the Anthropocene? GSA Today 18, 4-8. doi: 10.1130/GSAT01802A.1

Zhang, K., Dearing, J. A., Tong, S. L., and Hughes, T. P. (2016). China's degraded environment enters a new normal. Trends Ecol. Evol. 31, 175-177. doi: 10.1016/ j.tree.2015.12.002

Conflict of Interest Statement: The authors declare that the research was conducted in the absence of any commercial or financial relationships that could be construed as a potential conflict of interest.

Copyright (C) 2018 Power, Codding, Taylor, Swetnam, Magargal, Bird and O'Connell. This is an open-access article distributed under the terms of the Creative Commons Attribution License (CC BY). The use, distribution or reproduction in other forums is permitted, provided the original author(s) and the copyright owner(s) are credited and that the original publication in this journal is cited, in accordance with accepted academic practice. No use, distribution or reproduction is permitted which does not comply with these terms. 